\title{
Spatial analysis of Samara region land degradation and differentiation of antierosion territory organization
}

\author{
E. V. Samokhvalova, S. N. Zudilin*, and O. A. Lavrennikova \\ Samara State Agrarian University, Kinel, Samara region, 446442, Russia
}

\begin{abstract}
In the research, a spatial analysis of the degradation of Samara region agricultural land with the assessment of economic losses due to water erosion is carried out. A map chart of the distribution of districts with different degrees of erosion has also been developed. The values of the degradation factor coefficient and economic losses due to the influence of erosion processes are calculated. The key points of antierosion territory organization and land regulation depending on landscape nature and kind of damage are represented. The plan of action for the antierosion territory organization of a farm in Kinelsky district is proposed and its effectiveness to stop and prevent erosion processes, as well as for rational use of land and increase soil fertility is shown.
\end{abstract}

\section{Introduction}

Water erosion, as a natural process of moving soil solid matter and ground due to the influence of water flows, occurs almost everywhere. It is typical for most agricultural regions of Russia. Its consequences appeared in the form of soil degradation depending on the topography and afforestation of the land, the soil cover, and climate characteristics. Farming operation dramatically enhances this process, breaking the natural regeneration of landscapes and depriving the soil of natural vegetal protection.

There is a physical soil depletion, which leads to fertility fall, and sometimes to complete destroying of the soil cover. In the economically developed lands, erosion is a source of environmental pollution by chemical soil components and introduced pollutants. It is one of the primary cause of the siltation of small rivers and degradation of agricultural landscapes. Antierosion protection is the key step in the conservation and rational use of land resources.

According to the data [1], $26.6 \%$ of Samara regional agricultural land has water erosion processes and the area continues to increase up to almost 1132 thousand ha or $29.7 \%$, including arable land, which is 764.6 thousand ha or $29.5 \%$. Besides, agricultural land on an area of 819.4 thousand ha or $21.4 \%$ is erosionhazardous, including arable land, which is 673.3 thousand ha or $22.7 \%$.

According to the results of soil surveys, eroded soils make up $53.6 \%$ of the total area of the region. They include $34.6 \%$ weakly eroded, $12.6 \%$ medium eroded, and $5.6 \%$ heavily eroded soils. The soils of the eastern and southeastern regions of the region are the most eroded, in which washed down soils occupy $60-63 \%$ of the area. In the western regions, they are much less and contain $27-40 \%$.

We need to strengthen the complex of antierosion measures, to develop land management projects to ensure the compliance of economic activity with the natural properties of the territory, its resistance to anthropogenic influences. All these measures are an important component of soil conservation as a naturaleconomic complex, and organizing rational land use, which becomes increasingly important in Russia now, during the period of land reforms on a difficult geopolitical situation and global economic crisis background [3]. The information basis for solving these tasks is the data from soil surveys, ecological land monitoring, a complex analysis of natural properties, and degradation processes.

The aim of the research was a spatial analysis of the agricultural land degradation in Samara region with an assessment of economic losses because of water erosion, and the development of a plan of action for territory organization and antierosion soil protection.

\section{Materials and methods}

Samara region is located in the southeastern part of the East European (Russian) Plain, in the middle course of the Volga river, which divides the territory into the rightbank and left-bank parts. The right-bank forest-steppe is part of the Volga Upland. It is a high plateau deeply dissected by a ravine-girder and river network, and a sharply defined shaft-like uplift - the Zhiguli Mountains. The left-bank part is characterized by a rugged large-

Corresponding author: zudilin_sn@mail.ru 
wavy landscape with a gradual increase from west to east, gradually turning into a wavy plateau, forming the eastern edge of the Russian Plain. It includes the Bugulmino-Belebeyevskaya Upland, which covers the northeast of the Samara Region, and the spurs of Obschiy Syrt, which are the western slope of the South Ural Ridge and further south of the river Samara.

Climatic conditions are formed mainly under the influence of atmospheric processes from the Asian continent and the Atlantic Ocean. Hot summers, long and frosty winters, moisture deficiency, moderately intense wind activity, and relatively high insolation are the defining characteristics [4].

Under the influence of the western air mass transport and periodic invasions of Atlantic cyclones, the conditions of the continental climate soften. All these factors create a significant variety of conditions developing over time, having latitudinal peculiarities and reflecting the effect of local factors (topography, hydrography, afforestation). Differentiation of the natural conditions of Samara region is shown by the allocation of three natural agricultural zones: foreststeppe, steppe, and dry-steppe (Fig. 1) [5].

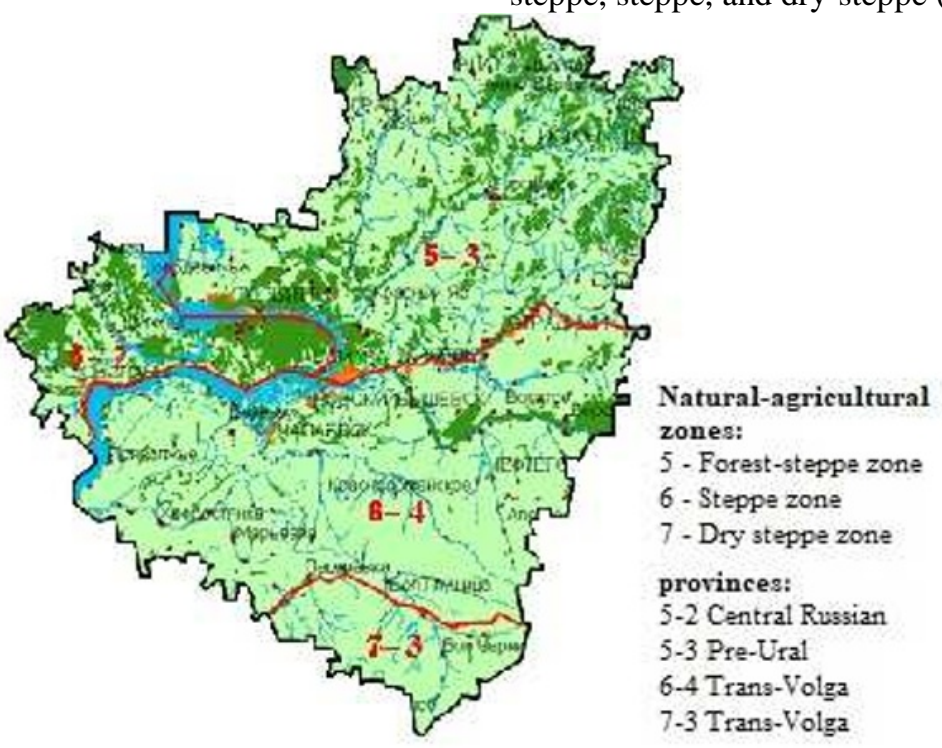

Fig. 1. Natural-agricultural zones of Samara region

In the structure of the soil cover of Samara Region, black soils (chernozems) dominate ( $97.5 \%$ of the arable land area): leached, typical, ordinary, southern. Their distribution over the territory is subject to the laws of zonality with a gradual decrease in the level of fertility from the northern to the southern districts [5]. In addition, a decrease in fertility occurs under the influence of a number of negative processes (soil erosion, water-salt misbalance, stone clogging, and others), which have been developed differently in the landscapes of the region.

To assess the degree of land degradation, each administrative district of the region was given a level of degradation and a score (from 0 to 5) based on the shortage of winter wheat productivity as the key food crop in the region. According to the methods [6], a shortfall of $50 \%$ (productivity reduction factor 0.5 ) or more is considered as catastrophic consequences of degradation (5 points). Calculations show that erosion damage of up to $60 \%$ of the area and more corresponds to this level. The remaining levels are set proportionally. The assessment of economic losses was carried out according to the scale and degree of soil damage [1], taking into account the productivity decrease coefficients of grain crops [7].

\section{Results and discussion}

\subsection{Spatial analysis of degradation and erosion zoning}

According to the data [1], there are water erosion processes in all administrative districts of Samara region. The area of damage to agricultural land varies widely from 1.5 to almost $50 \%$. The land degradation degree in this case is estimated in the range from 0 to 4 points (map chart on figure 2). A catastrophic level of damage (5 points) was not detected in any of the districts.

The highest level of degradation (4 points) is observed in Pohvistnevsky and Kamyshlinsky districts and a little smaller ( 3 points) in Kinel-Cherkassky district, where on the slopes of the BugulminoBelebeyevskaya Upland, dissected plains of the right bank of the Bolshoy and Maly Kinel rivers, intense and destructive flows of meltwater and rainfall form. Damage with a score of 3 points are also noted in the southernmost Bolshechnerigovsky district, which is connected with developed ravine erosion and the influence of the spurs of General Syrt. 


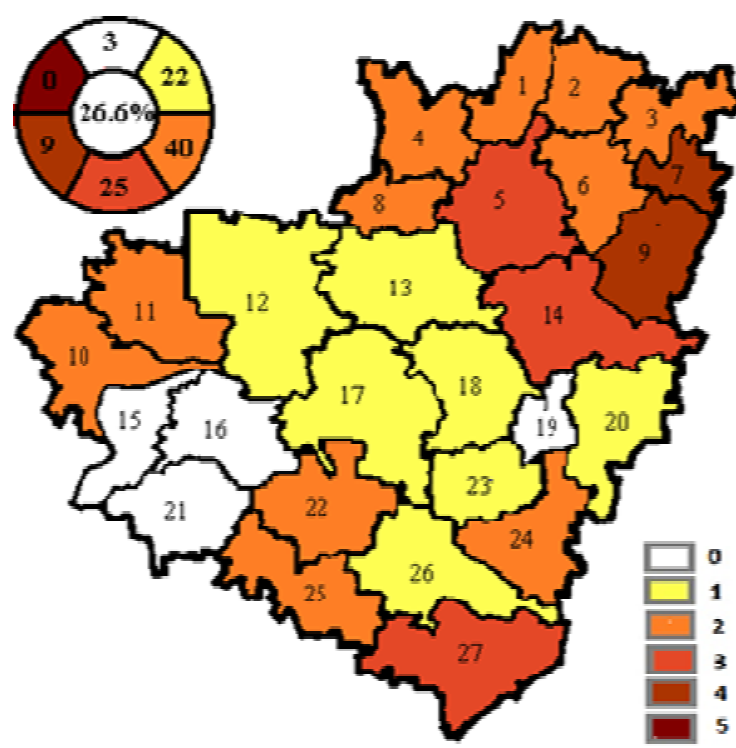

\section{Administrative districts:}

1 - Chelnovershinsky,

2 - Shentalinsky,

3 - Klyavlinsky,

4 - Koshkinsky,

5 - Sergievsky,

6 - Isaklinsky,

7 - Kamyshlinsky,

8 - Elkhovsky,

9 - Pohvistnevsky,

10 - Syzransky,

11 - Shigonsky,

12 - Stavropolsky,

13 - Krasnoyarsky,

14 - Kinel-Cherkassky,
15 - Privolzhsky,

16 - Bezenchuksky,

17 - Volzhsky,

18 - Kinelsky,

19 - Bogatovsky,

20 - Borsky,

21 - Hvorostyansky,

22 - Krasnoarmeysky,

23 - Neftegorsky,

24 - Alekseevsky,

25 - Pestravsky,

26 - Bolsheglushitsky,

27 - Bolshechernigovsky

Fig. 2. The degree of land degradation in Samara region under the influence of water erosion

Generally, in the region, there are $9 \%$ of the land with a very high level of degradation (rated at 4 points) and $25 \%$ with a high level ( 3 points). The most common (in 11 districts, $40 \%$ of the degradation area) agricultural land with a medium level of degradation (2 points). In 7 of 27 districts (22\% of the degradation area), a low level of degradation is detected (1 point), and in 4 districts ( $3 \%$ of the degradation area), it is conditionally absent ( 0 points), they are predominantly located in lowland floodplain terraces of the Volga and Samara rivers. The productivity decrease coefficient in damaged areas is $0.88-0.93$. The decrease in average local productivity is from 0.96 to almost 1.00 .

Taking into account the differentiation by the district of bioclimatic potential (BCP) of the region [8], calculated by the set of recommended for cultivation crops, and the productivity decrease coefficient, we obtain the distribution of economic losses because of land degradation. With a BCP value of $28.0 \mathrm{c} /$ ha, reduction in yields amounted to almost 70 thousand tons of products in grain equivalent for the region. The districts of the forest-steppe zone of the region are characterized by the highest BCP value $(28.4 \mathrm{c} / \mathrm{ha})$ and the largest area of eroded land $(31.1 \%$ of agricultural land). There are losses of almost 40 thousand tons of products there.

A particularly significant contribution (8.2 and 8.0 thousand tons) is made by Sergievsky and Pokhvistnevsky districts with a high productivity potential (32.6 and $29.0 \mathrm{c} / \mathrm{ha}$ ) and a degradation level of 3 and 4 points. In addition, significant scales of eroded land in the districts of the dry-steppe zone, especially in Bolshechnerigovsky district (assessment of the level of degradation of 3 points, $40.4 \%$ of agricultural land) pay attention.

Considering the relatively low productivity potential (24.6 c / ha) and the significant area of agricultural land, the extra yield will provide an increase in agricultural production by 7.3 thousand tons in grain equivalent. A smaller effect is suggested by erosion-protective measures in the districts of the steppe zone, as the degradation degree there is not so significant. The only exception is Kinel-Cherkassky district with a degradation level of 3 points $(37.7 \%$ of agricultural land). The extra yield there can provide up to 6.0 thousand tons of products in comparison with Kinelsky district with a degradation level of 1 point, where an extra yield is $0.32 \mathrm{c} / \mathrm{ha}$ or 0.7 thousand tons in grain equivalent.

Thus, a detailed systematization of land resources with an assessment of the land degradation degree and the scale of economic losses is necessary for the economic justification and planning of a set of landimprovement, soil-protective, and land management activities. Geospatial analysis of eroded land gives reason for ranging districts according to the potential effectiveness of measures to soil recultivation and antierosion protection.

At the same time, the solution of the issues of development and implementation of differentiated systems of measures to control soil erosion and the determination of directions for the rational production use of land are predicated upon the basis of data on monitoring the ecological condition of the land, results of soil surveys, analysis of agrolandscape changes.

\subsection{Elements of the anti-erosion management of the land}

It is known that the potential danger of erosion is mainly determined by the distribution of land along the surface slopes. Without special erosion control measures, erosion already appears on slopes with a steepness of $1^{\circ}$, and sometimes even $0.5^{\circ}$. That is why taking into account the topography in land management in areas of land erosion is of great importance. Also, we have to take into account the fragmentation of the territory, the steepness of the slopes, and their exposure, the depth of local bases of erosion [9]. In this regard, a slope steepness map, soil survey data, erosion and erosion 
resistance assessments, and other detailed documents are developed for further use [10].

Depending on the erosion of the arable land and the length of the slopes, approximately $2.5-3.0 \%$ of arable land along the boundaries of the working plots and fields is provided under the forest belts. Types and structure of the protective forest belts are determined depending on the partition coefficient of the territory.

While meeting the mandatory requirement of minimum, but sufficient forest belt areas to control erosion processes together with other antierosion measures, in areas of soil erosion, the percentage of afforestation depends on the coefficient of fragmentation of the territory and erosion of arable land. Besides, the partition coefficient of the territory fairly determines the types of protective forest belts and their structure. Thus, with a represented fragmentation of the territory, the larger proportion will have the ravine and gorge forest belts, and with a small fragmentation and with an increase in the length of the slopes, the proportion of the water-regulating forest belts will expand.

The correct establishment of economic and on-farm specialization is important for the antierosion organization of the territory [11]. It implicates determining the degree of concentration and level of production intensity, the optimal size, and the combination of industries. For example, specialization in crop production determines the structure of crops, taking into account the coefficient of erosion hazard of plants, the issue of types, aspects and amount of crop rotations is considered.

In the eroded area, which goes together with a large development of the territory, where the possibilities for the industrial use of new land are almost exhausted, the design of the composition and structure of the land focuses on the placement of crop rotation. They are fields and plots taking into account the erosion hazard of the territory, the positioning of areas for shelterbelt forests, hydraulic engineering antierosion facilities, and road network.

In general terms, the arrangement of the crop rotation area is crucial in improving the efficiency of agriculture, since arable land is the main and most productive land in agricultural enterprises. Using the map chart of erosionhazardous lands, we can determine the areas that are appropriate to use for soil protection, field, or other crop rotation.

For example, on lands where the disposal intensity can reach 15-20 t / ha (IV and V erosion hazard categories), soil-protective crop rotations with a large percentage of perennial grasses have to be designed.

The production of row crops and spring crops on these lands is useless, as productivity drops down and erosion processes intensify. If such lands occupy a small area or are located within the small lots on the territory, they can be included in a field crop rotation.

Besides, eroded lands are allocated to separate working plots where perennial grasses and winter crops are placed according to the crop rotation scheme (assembly fields). Under field crop rotation, packed with row crops and other intensive crops, the main areas of arable land, the best in terms of soil and topography, located in large and compact groups are used.

\subsection{Territory organization and development of antierosion measures}

The organization of the territory and the development of antierosion measures are carried out after a complex analysis of the land-use territory and related conditions. The principle of differentiated use of arable land depending on the level of soil fertility, the erosion degree and topography is meaningful. When developing tillage systems, we have to consider an unequal soil protection ability of crops, their different reaction to the soil erosion level, the differentiation of arable lands according to the intensity of use depending on the steepness of the slope.

Through the example of particular land use, relevant studies have been carried out. The object is an agricultural production cooperative named after Kuibyshev in Kinelsky district of Samara region. The farm belongs to the watershed upland (syrt) steppe of the Trans-Volga region and is located on the left bank of the Samara River.

In general, the territory has flat and sloping terrain types. Slopes from $1-3^{\circ}(76 \%)$ of the total farm area are predominant. Slopes with a steepness of $3-5^{\circ}$ account for $19.7 \%$ of the research area. The agricultural landscape is characterized by a high level of plowghness, which promotes the development of erosion processes. The soil cover is mainly represented by ordinary medium-thick chernozem, with loam and heavy loam granulometric composition.

The landscape can be best characterized by morphometric indicators recorded on the corresponding maps.

The intensive development of geoinformation technologies can significantly simplify the production of mass quantitative material regarding the topography. Therefore, at present, the electronic representation of the landscape is widely used, which in the context of geoinformation systems is represented by digital terrain models. Creating a digital terrain model is an additional and informative action allowing you to solve a lot of land management tasks.

The main stages of the study were the following: collection of primary material as a soil map of Kinelsky district of Samara region; topographic maps; space images posted in the public domain on the Internet; field material analysis; creation and analysis of a statistical information base; creation of thematic maps; development of a terrain digital model; soil outwash calculation.

According to the data of the latest soil survey conducted in 2011, average-weighted humus content in the soils of the farm was $3.2 \%$, mobile phosphorus was $128 \mathrm{mg} / \mathrm{kg}$ of the soil, and exchange potassium was 124 $\mathrm{mg} / \mathrm{kg}$. There were $23.4 \%$ (1601 ha) of land with very low, $58.1 \%$ (3972 ha) with low, and $18.5 \%$ (1264 ha) with medium humus content.

The soils with a high and very high phosphorus content dominated, and $33.5 \%$ (2291 ha) of soils had a 
high content of potassium. Analysis of the dynamics of soil fertility on the farm showed that there was a decrease in the area of low-humic soils by $23.1 \%$ and an increase in slightly humic soils by $22.9 \%$.

When designing crop rotations, the main source and resulting geospatial data are landscape; agricultural production groups of soils; agricultural plots; ecological and technological groups of arable land, which take into account the potential danger of erosion processes and the intensity of land use.

Calculations of the potential intensity of soil outwash in different crop rotations were carried out along the runoff lines based on the compiled slope steepness map (Fig. 3). When calculating, we used the steepness and exposure indicators of the slope, the length of the runoff line, the type and the granulometric soil composition, and the compliance to outwash.

There are the following expositions of slopes on the land use territory: northern, northeastern, southern, western, southeastern. Slopes with a length of $750 \mathrm{~m}$ and a steepness of up to $3^{\circ}$ dominate in the upper part of the land. Slopes with a steepness of $3-5^{\circ}$ account for $19.7 \%$ of the study area. The weighted average soil outwash in crop rotations is $13 \mathrm{t} / \mathrm{ha}$, which corresponds to the II category of land erosion hazard.

Three antierosion complexes have been designed on the farm's territory. Agrocomplex No. 1 is used on soils subject to a weak degree of erosion processes and

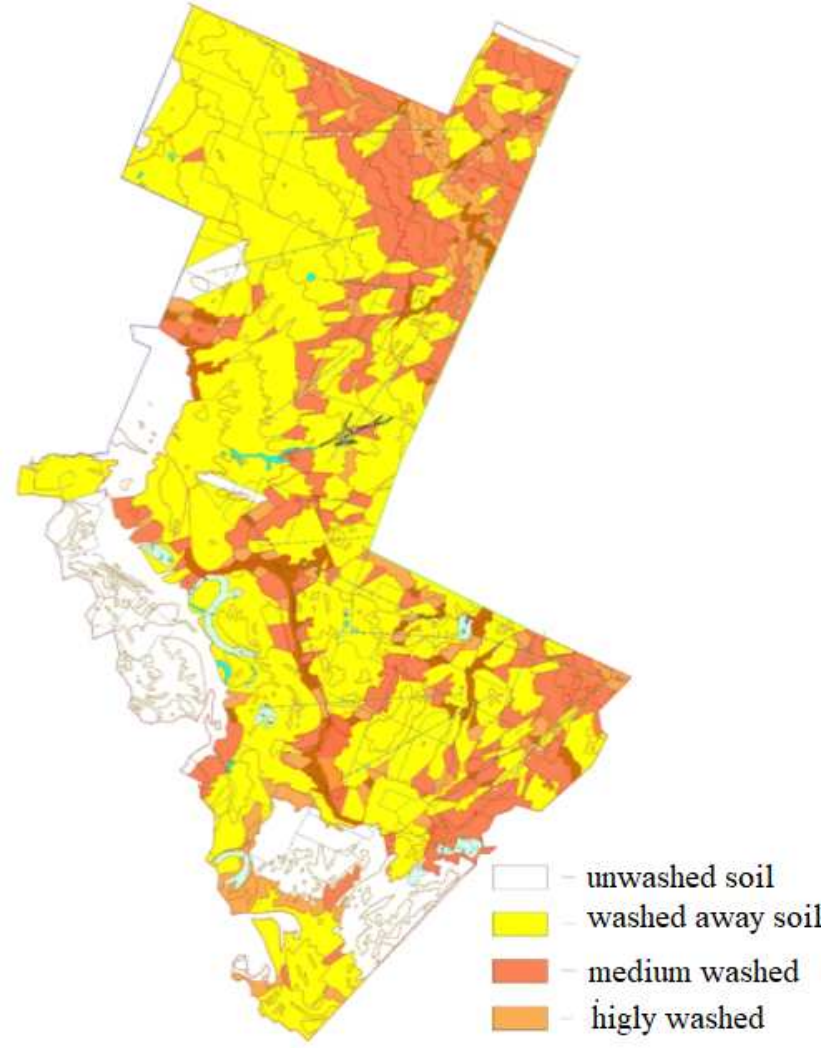

Fig. 3. Slope steepness map potentially dangerous concerning the development of erosion. Agricultural complex No. 2 is provided for soils subject to moderate and severe erosion. Agrocomplex No. 3 is provided for degraded lands.

Figure 4 shows a scheme of the antierosion organization of crop rotations. The placement of crops in crop rotations is performed differentially, taking into account their exposure to erosion. On lands of erosion hazard categories I and II, field and fodder crop rotations are placed with a predominance of grain and row crops. The outwash value is in the range of 5.6-9.8 $\mathrm{t} / \mathrm{ha}$.

The share of lands belonging to categories III and IV is $22.7 \%$ and $5.4 \%$, respectively. They contain field and soil protection crop rotations with cereals of continuous sowing and perennial grasses. There are no lands of the category $\mathrm{V}$ of erosion hazard on the farm.

The analysis of the results allows us to make a conclusion that the differentiated placement of crops on arable land is more effective than the one without taking into account the topography and land categories.

The soil outwash decrease by an average of $0.72 \mathrm{t} /$ ha was registered. The extra yield to the differentiated placement of crops amounted to 1.14 thousand rubles per hectare.

Thus, the antierosion farm territory organization has to provide conditions for the control and prevention of erosion processes, rational use of land, and increase soil fertility.

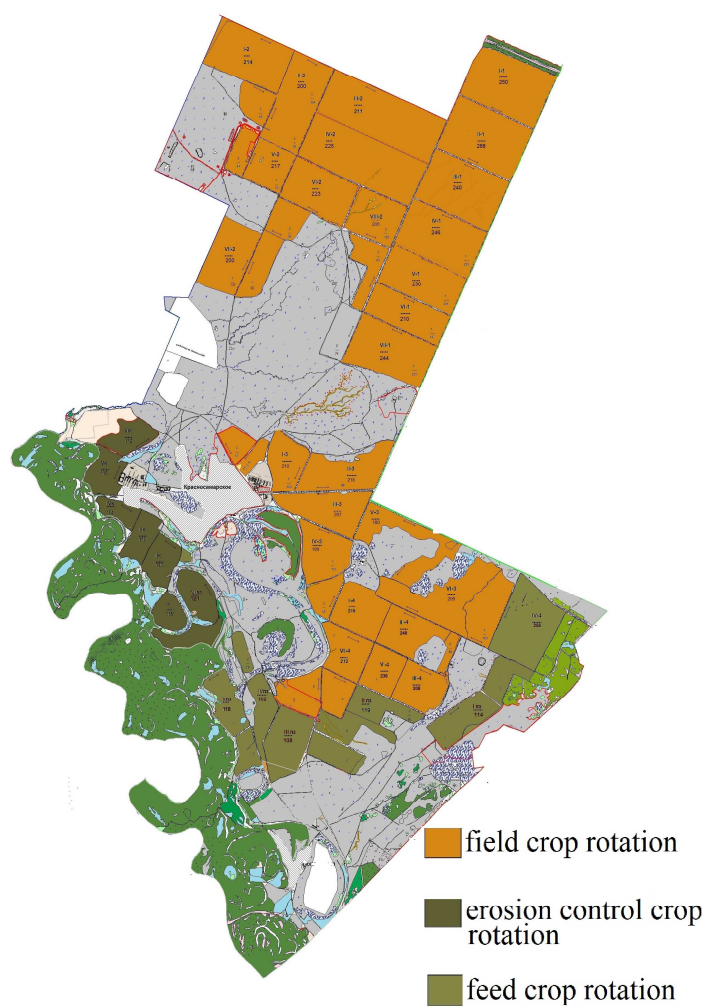

Fig. 4. Crop rotation map 


\section{Conclusion}

While we notice the continued development of erosion processes and an increase in the land degradation area, it is necessary to recognize the insufficient effectiveness of the current erosion control measures. Great efforts are required for the correct justification, development and implementation of a complex of measures to control soil erosion, as well as their spatial differentiation and assessment of effectiveness.

Geospatial analysis of land degradation, assessment of districts for the potential effectiveness of antierosion protection, integrated erosion zoning of the territory represent an informational basis for the economic justification and planning of a set of land-improvement, soil-protective, and land management activities.

At the same time, plans for the antierosion territory organization are expected to be interconnected with projects of on-farm land management, thus providing the concurrency of economic activity to the natural properties of the territory, its resistance to anthropogenic impact.

\section{References}

1. L.N. Poroshina, ed., Atlas of lands of Samara region (Russian Research and Design Institute of Land Resources, Samara, 2002) 99 p.

2. V.V. Malikov, Report on the condition and use of land in Samara region in 2017 (Department of the Federal Service for State Registration, Cadastre and Cartography in Samara Region, Samara, 2018) 77 p.

3. S.N. Volkov, N.V. Komov, V.N. Khlystun, How to achieve the effective land management in Russia? Int. Agricultural J., 3, 3-7 (2015)

4. B.G. Sherstyukov, V.N. Razuvaev, A.I. Efimov, O.N. Bulygina, N.N. Korshunova, E.G. Apasova,
L.G. Anurova, L.V. Shurueva, The climate of Samara region and its characteristics for climatedependent fields of the economics (Volga UGMS, Samara, 2006) 167 p.

5. N.I. Nesmeyanova, S.N. Zudilin, A.S. Borovkova, Soil cover of Samara region and its qualitative assessment (PPC of Samara State Agricultural Academy, Samara, 2007) 124 p.

6. D.A. Shapovalov, P.V. Klyushin, A.A. Murasheva, Methodological fundamentals of land monitoring: a training manual (Federal University on Land Management, Moscow, 2010) $238 \mathrm{p}$.

7. A.K. Ogleznev, T.A. Kupriyan, T.E. Norkina, A.V. Melnikov, A.A. Fadeev, A.Z. Rodin, S.I. Nosov, D.S. Bulgakov, I.I. Karmanov, L.A. Karmanova, O.V. Mikhailova, A.L. Overchuk, S.G. Miroshnichenko, Quality assessment and classification of land according to their suitability for agricultural use (practical guide) (VISHAGI, Moscow, 2007) 80 p.

8. E.V. Samokhvalova, The bioclimatic potential of the territory in the cadastral valuation of agricultural lands (the case of Samara region), Meteorology and hydrology, 4, 102-112 (2017)

9. D.N. Kutliyarov, A.N. Kutliyarov, R.F. Kutliyarov, Improving the efficiency of agricultural land use, in: Materials of the Int. Sci.Pract. Conf. "Agricultural science in the innovative development of an agricultural sector" (BSAU, Ufa, 2015) pp. 226-230

10. O.P. Yermolaev, Geoinformation mapping of soil erosion in the Middle Volga region, Eurasian Soil Science, 50, 118-131 (2017) DOI: $10.1134 / \mathrm{S} 1064229317010070$

11. A.I. Chursin, K.V. Nezvanova, Methods of soil degradation control in the Russian Federation, Int. J. of Appl. and Fund. Res., 6-1, 88-91 (2016) 